\title{
Chronic Endometritis and Chronic Metritis in Virgins.*
}

\author{
By Archibald Donald, M.A., M.D., C.M., Gyncecological Surgeon \\ to the Manchester Royal Infirmary, and Surgeon to St. Mary's \\ Hospital for Women, Manchester.
}

IT is not an easy matter to find a title which will indicate precisely the subject dealt with in this paper. I wish to limit my remarks to changes in the endometrium and mesometrium which occur apart from the usual infective causes (sepsis, gonorrhoa and syphilis), and also to exclude tubercle, cancer, fibroid tumour and membranous dysmenorrhæa. The title I have chosen is somewhat clumsy and not without objection, but it probably conveys my meaning better than any other. "Idiopathic endometritis and metritis" is shorter, but is open to the objection which always attaches to the adjective. "Benign adenoma" is too limited in its application and involves a theory which all may not be inclined to accept.

Clinical Material. During the last few years, I have been taking notes of cases of so-called endometritis and metritis in virgins, and my observations, which $I$ have recorded in a tabular form, are based upon a fairly large series of cases ( 40 in all) which $I$ have carefully observed. In selecting the cases, I have rigidly excluded all but those that were absolutely above suspicion, and have only taken those in which the virginal condition was beyond doubt. It is true that the same kind of case is often found in married women who are sterile, but there must always be a doubt in such cases as to previous abortion or gonorrhœea. Further, my list is mainly composed of cases of which my notes have been fairly full, and which I have been able to keep under observation. For this reason most of them are cases in private practice.

Types of Cases. On passing the cases under review, I find that they resolve themselves into three groups. The first group (Cases 1 to 30 inclusive) is by far the largest, and is the one to which I wish to call special attention. It is characterised briefly: (1) by a small cervix; (2) by an acute flexion; (3) by enlargement of the body of the uterus. The cervix in these cases resembles the infantile cervix. It is often so small as

* Read at a meeting of the North of England Obstetrical and Gynæcological Society, 15th January, 1904. 
to be with difficulty seized and pulled down with the vulsellum if room has to be left for the passage of a sound. The supravaginal cervix is thin and soft, and the body of the uterus falls forwards or backwards so as to form an acute flexion. I do not divide the cases according to the forward or backward displacement, as I regard this as a mere accident. The small size of the cervix, and the way in which the uterus is doubled on itself, often gives rise to the impression that the organ as a whole is infantile, and if we trust to bimanual examination alone we are quite likely to come to this conclusion. It is only when the uterus is straightened by a vulsellum and a sound is passed, that we find the cavity is larger than normal.

In the second group (Cases 31 to 38 inclusive), the cervix is normally developed, but the body of the uterus is heavy, and there is retroversion, or exaggerated anteversion. In a number of cases the condition found was intermediate between these groups. It is naturally difficult to draw a hard and fast line between them.

The third group (Cases 39 and 40) is characterised by marked erosion and hypertrophy of the cervix, apart from any change in the condition of the body of the uterus.

Symptoms. The symptoms which I found in these cases may be classified according to their frequency. (1) Pain or dragging sensation in one or both iliac regions or pain generally in the lower part of the abdomen. I find this symptom recorded in 35 out of the 40 cases. Some of the patients complained of a feeling of discomfort, while in other cases there was distinct dragging or aching. In one case the patient had been operated on for appendicitis without any effect on the pain. Pain in the iliac region in my experience is very characteristic of forward or backward displacement of a heavy uterus, and too little attention has been directed to it. Pain or discomfort in that region is often referred to the ovary, but $I$ believe it is much more commonly uterine in origin. It is probably due to the dragging exercised on the broad and round ligaments by the displaced fundus of the uterus. (2) Dysmenorrhoea was almost as frequent as the iliac pain. It was noted in 33 out of 40 cases. It was often very acute, and in most cases had been present in a greater or less degree from the time of the first menstruation. (3) Leucorrhœea was noted in 32 out of 40 cases; it was sometimes slight, but in other cases formed the chief complaint. (4) Menorrhagia and Metrorrhagia were noted in 16 out of 40 cases. (5) Remote symptoms, such as headache, bladder troubles, difficulty in walking, sickness and nervous symptoms generally were present in a small proportion of the cases. 
Pathology.-My observations as regards the pathology of the condition have been limited to careful examination under anæsthesia (bimanual and sound) and to the examination, naked eye and microscopic, of tissue removed by the curette.

In a large proportion of the cases the uterine mucosa was much thickened. It came away in long thick strips of pale soft tissue. These strips sometimes measured an inch or more in length, one quarter of an inch in width, and an eighth of an inch in thickness. The cavity of the uterus was nearly always enlarged, the increase in size varying from a quarter to one and a half inches. The microscopic appearances will be described more fully by Dr. Fothergill, but we may mention that great increase of glands was generally found, but sometimes the inter-glandular tissue was increased. In some cases the mucosa was not much hypertrophied, but the uterine wall as a whole was thickened. In the majority of cases, therefore, we had to deal with a change in the uterine mucous membrane, accompanied by a thickening in the mesometrium. In a few instances the change seemed to be in the mesometrium alone.

Etiology. In passing from actual facts to theoretical considerations, the main problem which calls for solution is the correlation of the points observed in most of the cases, viz.: (1) the infantile cervix, (2) the uterine displacement, (3) the enlargement of the body of the uterus, and (4) the hypertrophy of the glandular lining. Much has to be worked out, but certain statements may be offered for consideration. We can understand that given a glandular hypertrophy, muscular hypertrophy will follow, according to the rules which govern the behaviour of all hollow muscular organs. It will also be admitted that an increase in the size of the uterus will favour the occurrence of displacements, and if the increased weight is in the body of the uterus, while the cervix is undeveloped, acute flexion will follow. The first stage in this process presents no unusual difficulty. It is quite as easy to understand why a young woman should have, without obvious cause, a glandular hypertrophy of the uterine mucosa as why she should have it in the glandular tissue of the tonsil, or in the post-nasal mucous membrane, or in the breast. It is simply an overgrowth of cells-a benign adenoma. The crux of the whole position is to account for the infantile condition of the cervix and lower uterine segment. It is possible that the insufficient development of the cervix and the stenosis of the external or the internal os causes retention of secretion, and by an irritative process sets up catarrhal change. It is easy to understand how the double condition 
of hypertrophied mucous membrane and narrow canal may cause hypertrophy of the mesometrium.

I have been unable to find any work on this subject of recent date, except that contained in the Archiv für Gynäkol. (Vol. lxvi., part 1, and Vol. lxx., part 2) by Theilhaber, Meier, and Lorentz. The theory advanced in these papers is that so-called chronic metritis is characterised by decrease of uterine muscle with increase of fibrous tissue, and of blood-vessels. Most of the investigations in these papers have nothing to do with the class of cases which we are at present considering. In Lorentz's paper nine cases are given. All of them were married women; seven of them had frequent confinements or miscarriages, and of the other two, one had been three times curetted before she came under observation, and the other one had a fibroid of the uterus. In his earlier paper, Theilhaber refers to cases of hæmorrhage and leucorrhœa occurring in young unmarried women. He attributes this to deficient muscular and excessive vascular development in the uterus, but his statements are not sufficiently supported by evidence derived from pathological investigation. Further, he attributes the early development of the blood ressels to masturbation, and he believes that rich diet, luxuriant habits, and over-indulgence in coffee, tea, and alcohol act as predisposing causes. So far as my observations have gone $I$ find nothing to suggest the practice of masturbation in any of the cases.

Diagnosis. The diagnosis in these cases is generally settled by vaginal examination, but in some cases, as has already been stated, it is necessary to make a more thorough examination under an anæsthetic. This raises the whole question of vaginal examination in young unmarried women. It is not necessary to go into this subject here. As a rule, in the cases we are considering the dysmenorrhea is so acute, or the symptoms so marked that the patient herself, and her friends, are anxious to have the matter fully investigated, and the medical man has no difficulty in deciding to do so. Cases of pure neurosis do not, as a rule, show the constant symptoms, or the association of symptoms that we have described. Further, in the cases of very young women we can always examine under anæsthesia and thus avoid any shock to the patient's feelings. The condition which most simulates that of chronic endometritis or ehronic metritis, is simple undevelopment of the uterus as a whole. In this, however, there is generally a history of prolonged absence of menstruation. It is well for obvious reasons that such a condition should not be left undiagnosed, and the physical examination will definitely settle the matter. 
Treatment. I think all will agree that little can be done by merely medical or palliative treatment for the kind of cases we are here dealing with. My practice has been to curette thoroughly under an anæsthetic, and with strict aseptic precautions, to wash out the uterus with sterilized water, and to pack for 24 hours with sterilized gauze. So far, I have had every reason to be satisfied with the results. Of the 40 cases $I$ have been able to follow up 26 . In 5 cases the operation has been performed too recently to justify any conclusion as to results, and from 9 other cases $I$ have had no report. Of the 26 cases, 14 are practically well; 10 cases are very much improved but still have some symptoms; while in only two cases has there been practically no improvement since the operation. It is interesting to note that as a rule some time elapsed before the full benefit of the operation was obtained, and that this period occasionally extended to six months. It is probable that the curetting sets up a change in the mesometrium, which is not fully completed for some months. In many of the cases $I$ have been able to note a distinct diminution in the size of the uterus, as measured by the sound, some time after operation. The symptoms which have most readily yielded to the treatment have been menorrhagia, leucorrhœe and the iliac pains, and dysmenorrhoea has been generally the last one to disappear. The most obvious alternative to curetting, and probably the measure most frequently employed is simple dilatation of the cervix. In my experience, the effects of this, even as regards the dysmenorrhœa, are very temporary, and it is manifestly not suited for cases in which in addition to stenosis there is also the glandular hypertrophy or thickening of the uterine wall. Incision of the cervix is open to the same objection. After this operation there is almost invariably cicatricial contraction, which leaves matters worse than before, and when the stenosis is at the internal os no plastic operation can be performed which will prevent this. The wearing of an intra-uterine stem is open to objection in the case of unmarried women, apart from the greatest objection that it is a continual source of danger.

When there is marked retroversion, or retroflexion, it might appear that ventrofixation would relieve the symptoms, but it is illogical to treat the displacement, which is merely a symptom of an unhealthy uterus, and at the same time to ignore the real cause of the trouble. As a matter of fact, in one of the cases in my list ventrofixation was done without the least effect on the patient's symptoms, and six years afterwards dilatation and curetting were sufficient to relieve her of trouble. Ventrofixation and curetting 


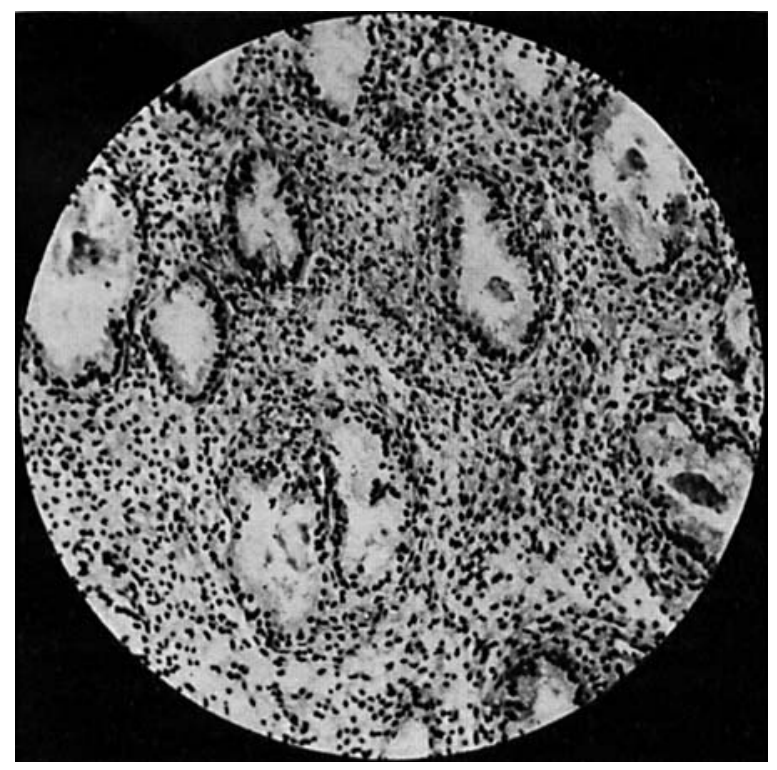

Fig, 1.-Section of a scraping from Case 14 in table.

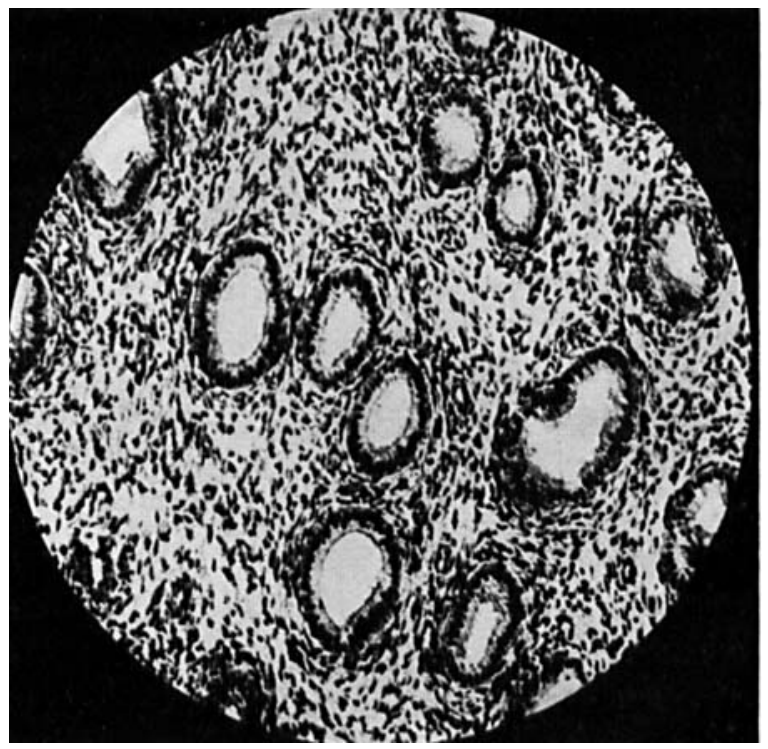

Fic. 2.-Section of a scraping from Case 30 in table. 


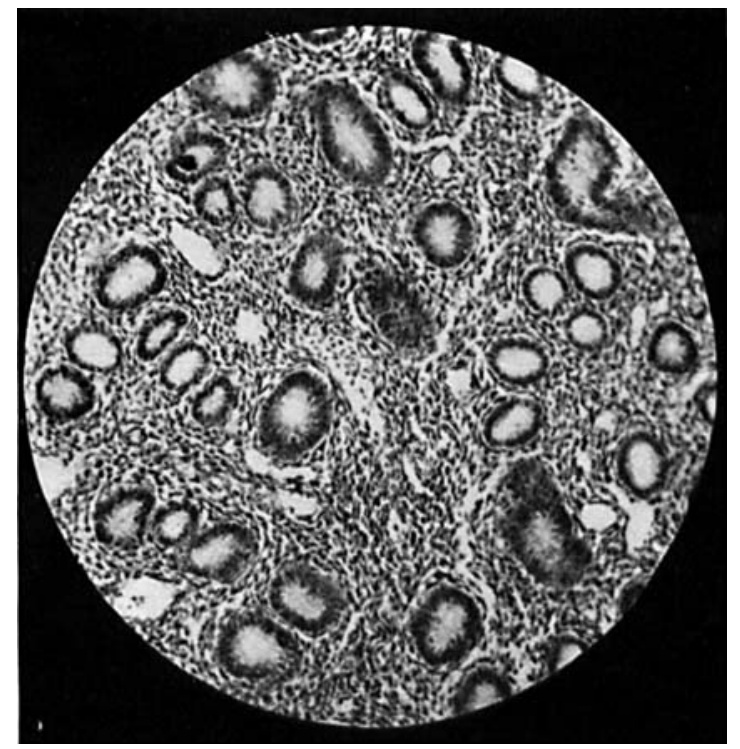

Frc. 3.--Section of scraping from Case No. 14 in table

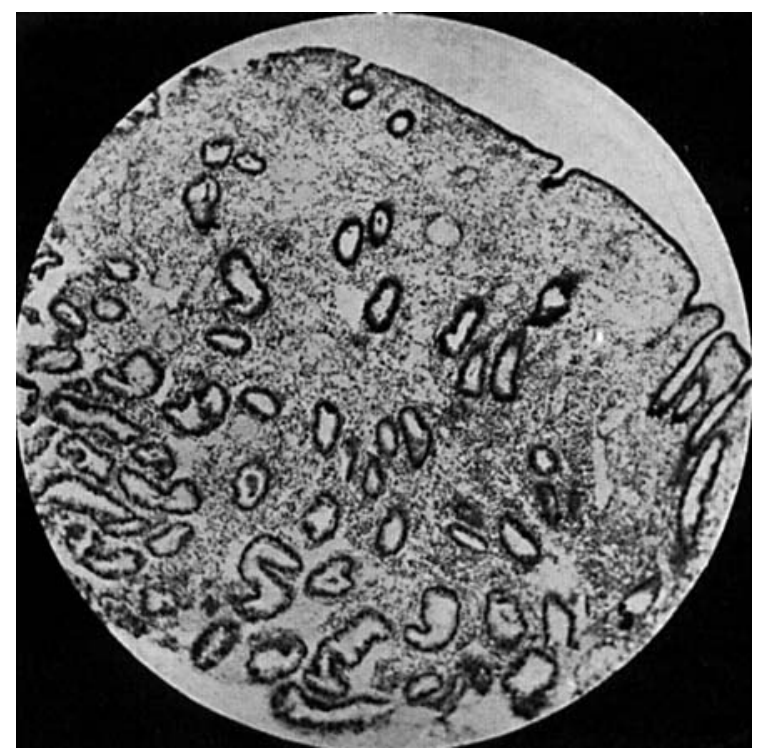

Fic 4. - Section of scraping from a case of hæmorrhagic endometritis showing extravasation of blood in stroma. 


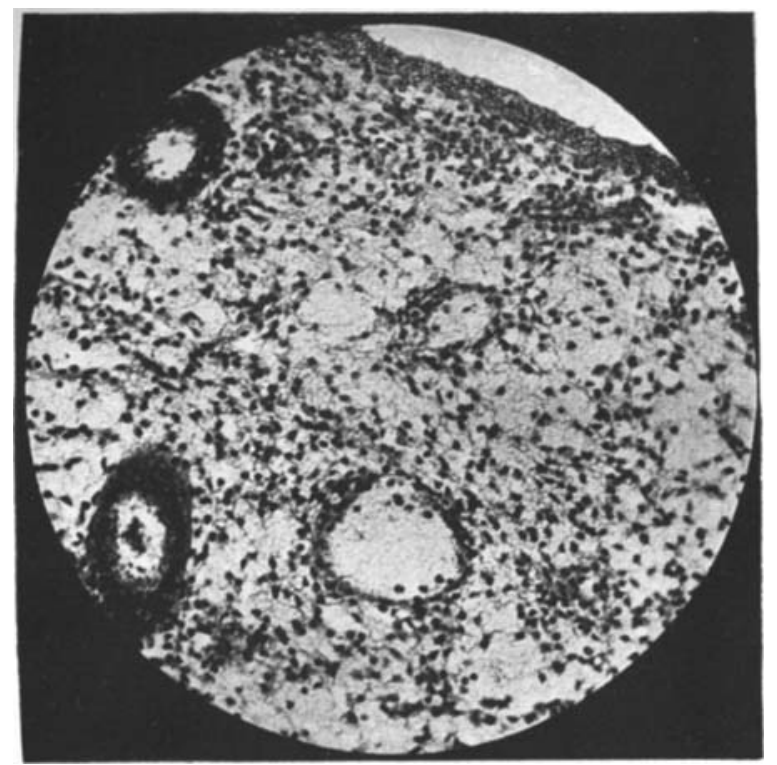

Fig. 5.-A portion of the field represented in Fig. 4 more highly magnified. 
together would no doubt be successful, but since good results can be obtained by the minor operation it seems unnecessary to do more.

The point which I wish to emphasize is that there is an unhealthy or abnormal condition of uterine tissues in these cases, and it is this condition which calls for treatment. It is not merely a temporary congestion, caused by stenosis or displacement, but an overgrowth of tissue. To limit the treatment to dilatation of a narrow cervical canal or to rectification of a displacement is quite insufficient.

In conclusion, I wish to state that the microscopic sections from which the illustrations for this paper have been taken have been mostly prepared by Dr. Fothergill, who has also given me valuable help by writing the report which follows. I am greatly indebted to Dr. David Orr, of Prestwich, for the excellent micro-photographs of the sections.

Report tpon Scrapings of Endometridu in Dr. Donald's Cases.

The material sent for examination consisted of portions of endometrium removed by the curette in a number of cases. The scrapings were pieces of tissue an inch to one and a half inches in length; their width corresponded to that of the curette used in removing them, and their thickness ranged up to one-eighth of an inch or slightly more. After fixing in 4 per cent. formalin solution, and dehydration by alcohol and aniline oil, the specimens were passed through xylol into paraffin. Sections were made perpendicular to the surface of the endometrium and were stained with hæmalum and eosin. The epithelium covering the surface of the mucosa and lining its glands does not show any important alterations. These cells are in a more active condition in some cases than in others, but in no case examined could the glandular epithelium be described as diseased. In one or two cases the glands were dilated. The blood-vessels are also practically unchanged in condition and in number. In some of the specimens examined the superficial portion of the mucosa contained extravasations of red-blood corpuscles into the inter-glandular connective tissue, but this, being a normal appearance during certain portions of the menstrual cycle, need not be regarded as pathological. The chief alterations observed are in 
the stroma or inter-glandular connective tissue of the endometrium. In this tissue more or less condensation is generally seen which may also be suggested by the term "fibrosis." Thus in normal endometrium the bulk of the connective cells have rounded nuclei and bodies, only a small proportion of them being recognisable as fixed connective tissue cells with spindle-shaped or stellate form. In most of the specimens under consideration this proportion is altered, the bulk of the connective tissue cells being spindle shaped and not rounded. The tissue has the appearance of granulation tissue advancing towards the formation of fibrous tissue, and is, in fact, a more advanced form of connective tissue than is the stroma of the normal endometrium. The first stage of this change appears to be a swelling or œdema of the tissue, for in certain cases the cells are rounded but are more widely separated than is normally the case.

Apart from the condensation of the stroma above described, the only change observed in these specimens is general hypertrophy of the mucosa. This is marked in all the specimens, the thickness of the endometrium being much increased. In some of the specimens there may be some relative increase in the number of glands, but this is not marked.

There is not in these specimens any inflammatory change; there is no increase in the number of leucocytes or degeneration of the nuclei or of the cell protoplasm.

Fig. 1 shows some irregularity in the outlines of the glands whose epithelium is actively secreting, the nuclei being near the basement membrane, the cell body being elongated, as a rule, into the lumen of the gland. The bulk of the connective tissue cells are rounded as in normal mucosa, but they are widely separated, apparently by serous effusions into the intercellular spaces.

Fig. 2 shows the condensation of the stroma, which brings the glands somewhat nearer together than they generally appear. Spindle-shaped cells are relatively very numerous between the glands, which are themselves normal. The two photographs, 1 and 2, give a good idea of the general overgrowth of the mucosa.

Fig. 3 represents a section from another case. The glands and capillaries are numerous and normal; but the stroma looks like young fibrous tissue, the spindle cells being arranged in concentric layers round the glands and vessels. 
Figs. 4 and 5 are from a section of a scraping from a similar case seen by Mr. Rodocanachi, and show the infiltration of the superficial part of the mucosa by extravasated blood. The light portions of the photographs near the surface epithelium are eosin stained red-blood corpuscles. The glands, capillaries, and underlying stroma are normal. Fig. 5 is a portion of Fig. 4 more highly magnified to show the red-blood corpuscles amongst the round cells of the stroma. Two capillaries, two glands and a portion of surface epithelium are included.

Note.-Fig. 3 is produced by permission of the Editor of the Practitioner. 


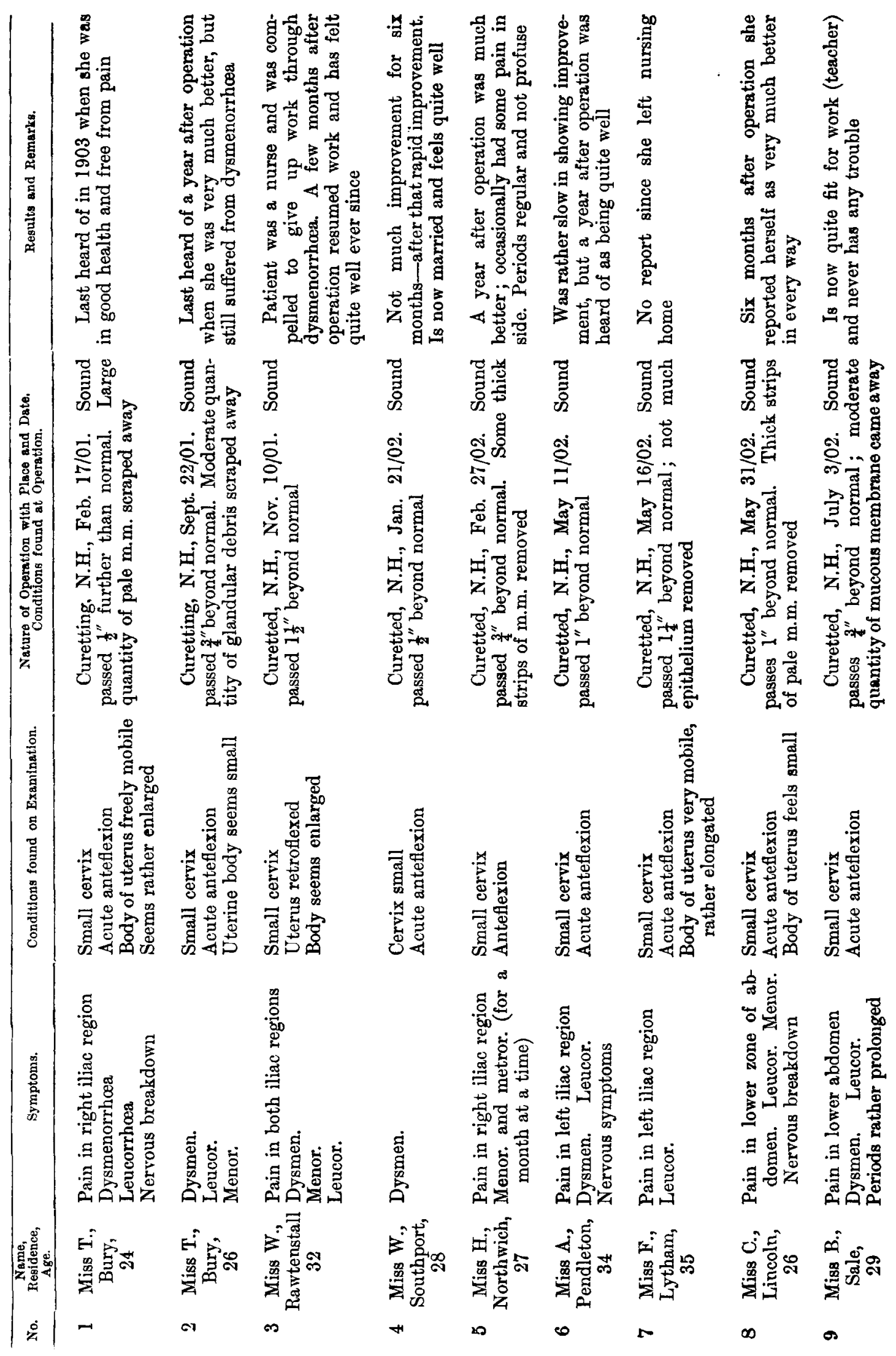




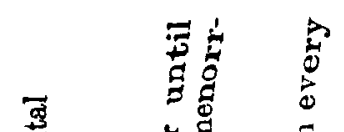

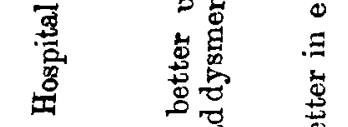

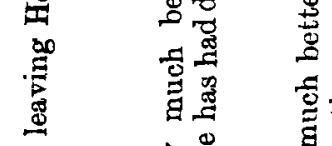

:

至

(5)

운

这范

造

सं 敋:

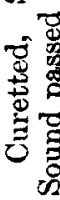

कें

劳 要

我蒙

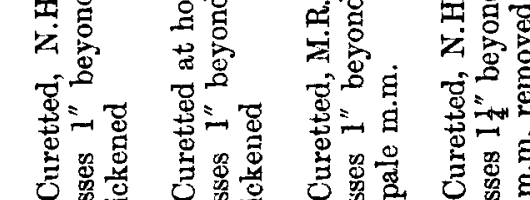

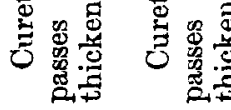

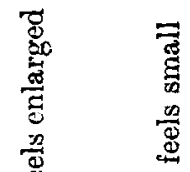

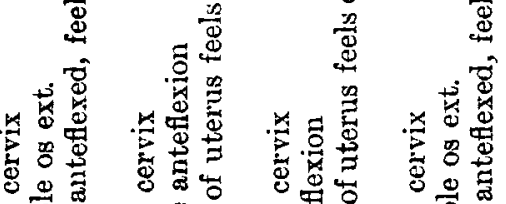

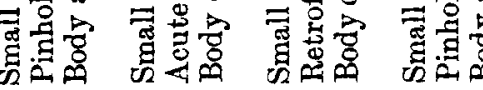

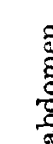

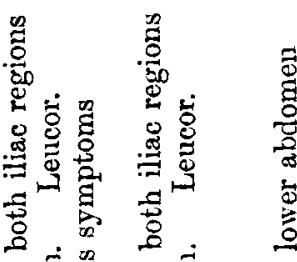

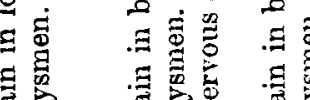

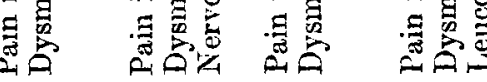

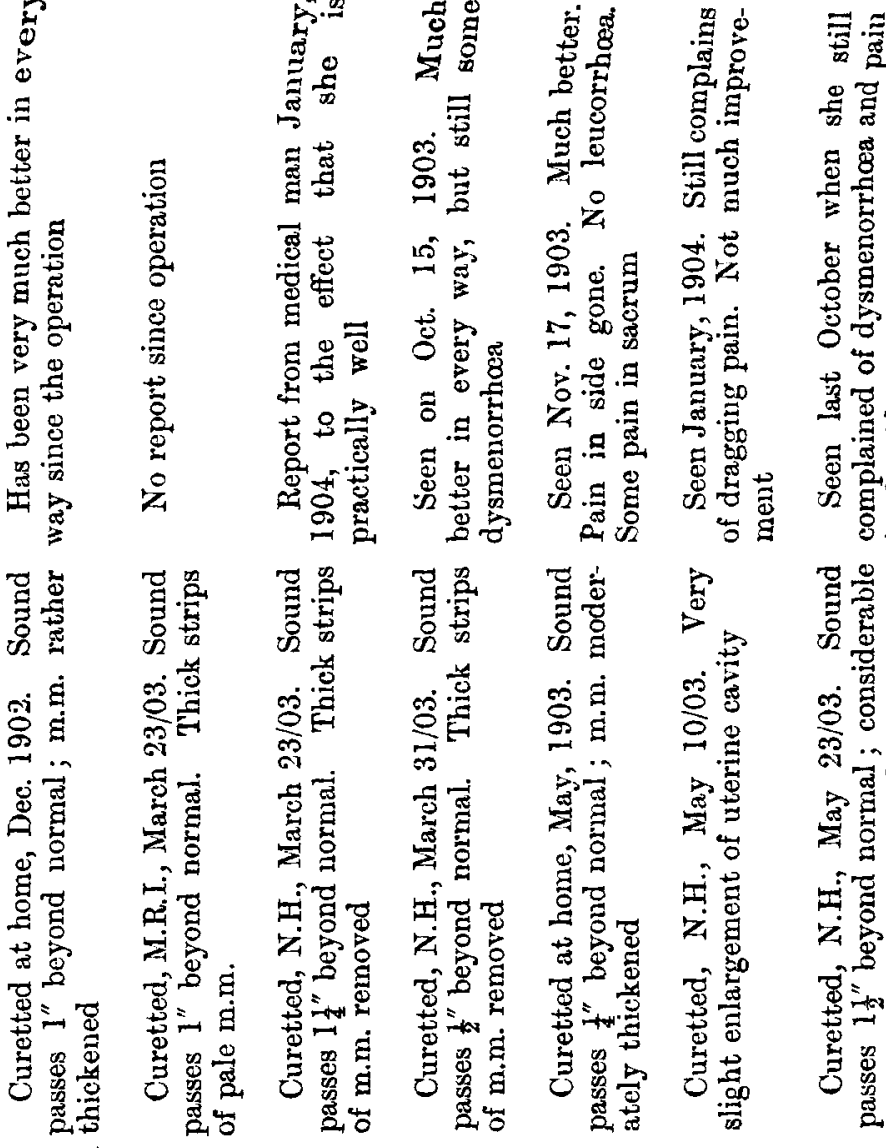

然

章

产

畄

离

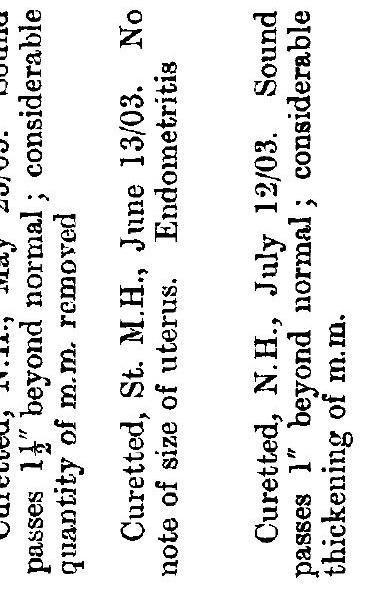

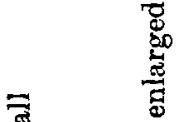

政

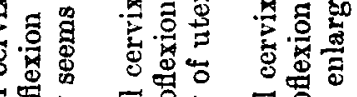

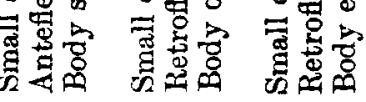

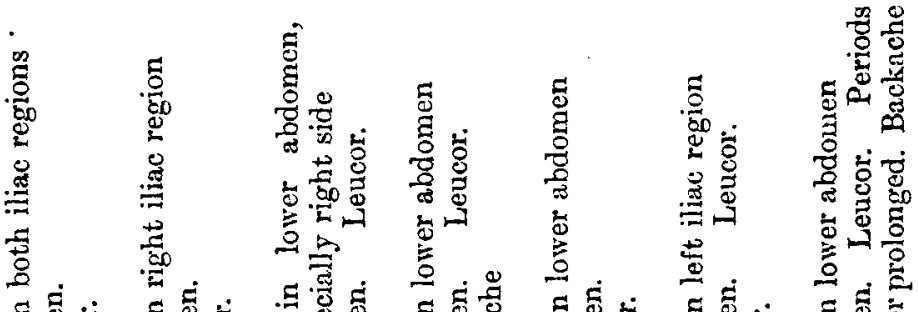

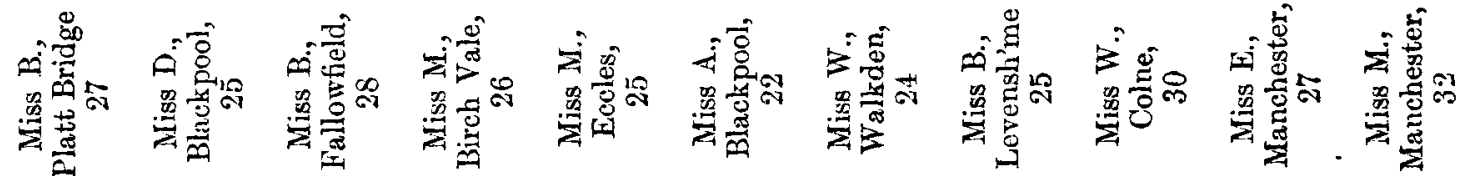

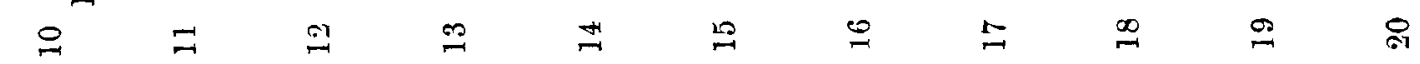




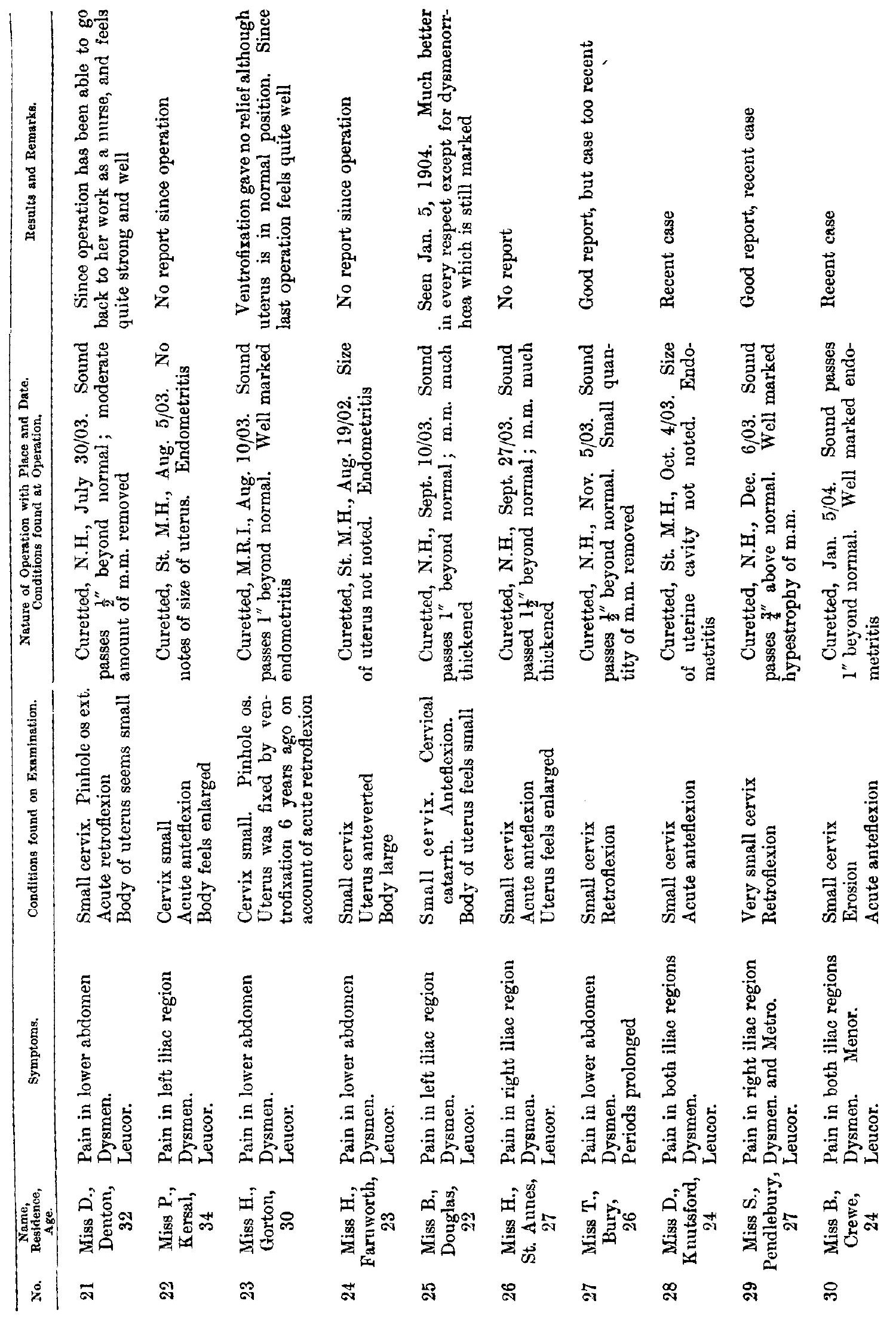


